\title{
Prevalence of B-Blockers Misuse for Exam Stress and Anxiety Management among Health Professions Students in Jeddah, Saudi Arabia
}

\author{
Asmaa Abdel Nasser ${ }^{1 *}$, Rahaf Hamad ${ }^{2}$, Haneen Mohammed ${ }^{2}$ and Butchi Raju Akondi ${ }^{3}$ \\ 'Faculty of Medicine, Department of Medical Education, Suez Canal University, Ismailia - 41111, Egypt; asmaa_mohamed@ \\ med.suez.edu.eg'dr.asmaashraf@gmail.com \\ 2Pharm D Internship, Ibn Sina National College for Medical Studies, Jeddah, Saudi Arabia \\ ${ }^{3}$ Department of Clinical Pharmacy and Pharmacology, Ibn Sina National College for Medical Studies, Jeddah, Saudi Arabia; \\ drraju2020@gmail.com
}

\begin{abstract}
Background: Excessive stress can affect students' learning performance and well-being. An optimal level of stress could enhance learning and achievement, whereas excessive stress may affect academic achievement and result in mental and physical health problems. This research aims to assess the prevalence of Beta-Blockers misuse especially propranolol and to determine the stress causative factors among health professions students. Methods: A descriptive cross-sectional study has been conducted at Jeddah, Saudi Arabia. Data collected through an online, modified and valid questionnaire through Google documents were sent to all health professions students. The total number of participants is 430. Results: The prevalence of propranolol misuse is $40 \%$ (172) among health professions students in Jeddah city and 89\% (153) of them were among the age group 20-30 years. The most causative stimulants to use propranolol among the medical students especially was for reducing the educational stress and anxiety $(70 \%)$ and they reported that they frequently used propranolol before oral/poster presentation (42\%) and entering the practical exams (OSCE/OSPE) (26\%) and oral exam (19\%) in comparison to the theoretical written exam (p-value < 0.01$)$. Conclusion: This study concludes that there is a high rate of propanol misuse among health professions students in Jeddah city especially among male medical students. All users were aware of the potential side effects of propranolol, however; the stress-relieving effect and feeling of propranolol increased its use prior to practical, oral and presentations exams.
\end{abstract}

Keywords: B-Blockers, Exam Anxiety, Exam Stress, Health Profession Students, Stress Management

\section{Introduction}

Stress is a consequence of or a general response to a certain action that places special physical or psychological demands or both on a person. Human beings can tolerate certain amounts of stress and have the ability to cope with this stress. Low amounts of stress (eustress) can have positive effects by energizing students towards their goal in academic achievement; however, excessive stress may seriously and negatively impact the student's health and educational performance ${ }^{1}$.

Excessive stress can affect students' learning performance and well-being. An optimal level of stress could enhance learning and achievement, whereas excessive stress may affect academic achievement and result in mental and physical health problems. In a study conducted in Brazil, stressors identified by students included lack of time, excessive curriculum content, oral and written assessments, an overload of extracurricular activities, competition among students and family and social problems ${ }^{2}$.

According to students in the health profession, the top stressors are practical oral exams and lack of time for them to study at home $e^{3}$. The life of students in the health profession has many stressors that might have an impact on their behavior, lifestyle and academic achievement. Therefore, these students tend to seek different stress-relieving methods and techniques. The most commonly used technique is the use of drugs, such as beta-blockers (propranolol), to overcome practical exam performance anxiety and stress ${ }^{4}$.

Propranolol (Inderal), a beta-adrenergic blocking drug, was developed by James Black in $1958^{5}$. Propranolol has potential

*Author for correspondence 
in the treatment of anxiety and stress. Preclinical studies have shown that propranolol has the capacity to selectively block the protein synthesis required for the storage of aversive (emotional) memory while sparing declarative memory (factual memory) ${ }^{6}$. Beta-blockers' mechanism of action is through blocking the action of endogenous catecholamines (epinephrine and nor-epinephrine) on the beta-adrenergic receptors part of the sympathetic nervous system, which mediates the "fight or flight" response. They are used to treat abnormal heart rhythms (arrhythmia) and prevent premature ventricular beats. Since they reduce the demand of the heart muscle for oxygen they may be useful in treating angina (chest pain), which occurs when the oxygen demand of the heart exceeds the supply. Beta-blockers are also used to treat high blood pressure and other heart diseases?

In some studies, propranolol is described as improving intellectual tractability and boosting exam performance. However, it is crucial to evaluate patients medically before prescribing a beta-blocker. Also, tolerability testing before the actual performance is of great value in inspecting these drugs' side effects. Propranolol, $10 \mathrm{mg}$ about one hour before the actual exam performance, is most often prescribed ${ }^{8}$.

A study conducted among students at a Dutch university showed that $(2.4 \%)$ of respondents reported the use of drugs several times for a non-medical purpose. Out of those, (61.1\%) reported the use of beta-blockers?. The use of beta-blockers to improve ones' exam results was reported by $(38.9 \%)$ of students, and out of those users, (19.4\%) used the medications without any medical indication. Another study among Iranian university students showed that (4.7\%) of participants had used propranolol ${ }^{10}$. Also, there was a study carried out with university students in Switzerland, where methylphenidate was reported as the most frequently used medication, reaching (4.1\%), followed by sedatives ( $2.7 \%)$ and beta-blockers $(1.2 \%)^{11}$.

There has been only one published study at a national level, about the prevalence of self-prescribing propranolol among medical and dental students in Riyadh, Saudi Arabia. This study showed a high rate of inappropriate use of propranolol. Also, this study revealed the medical students' point of view that this drug is very effective in reducing anxiety, which was more than for dental students. Although the majority of these students were aware of the potential side effects of self-use of B blockers without any medical indication, the anxiety-relieving effect that follows the administration of propranolol increased its use before oral exams and presentations ${ }^{4}$.

Considering the side effects and complications of propranolol, it is essential to understand the behavior of its misuse among health profession students, to detect the major causes for its frequent use and identify the means to overcome this behavior, especially before practical exams. Since there is a lack of studies in the region, conducted to identify the prevalence of propranolol misuse among health profession students, the present study can help establish baseline data in this regard in Jeddah city. Keeping in mind the drug safety concerns among Saudi health profession students, the study aimed to measure the prevalence of beta-blocker (propranolol) misuse among students in all health profession institutions.

\section{Methods}

\subsection{Study Context}

A descriptive cross-sectional study conducted at Ibn Sina National College for Medical Studies (ISNC), Jeddah, Saudi Arabia.

\subsection{Sampling}

We used a consecutive sampling technique among all students who were studying in health profession institutions (public and private colleges) in Jeddah, Saudi Arabia. The estimated online sample size for $30 \%$ prevalence of health profession students' misuse of propranolol for relieving stress revealed that our target sample should be 375 , but we collected data from 430 health profession students in Jeddah Saudi Arabia so as to increase the power of the sample.

\subsection{Data Collection Methods}

A modified online questionnaire was sent by Google survey form to all health profession students who were studying in Jeddah city, through different social media applications and different official groups for health care students. The inclusion criteria were healthcare students aged above 20 and up to 40 years old who were studying in Jeddah city. Exclusion criteria were non-healthcare students aged less than 20 or above 40 years old, and not studying in Jeddah city. Data collection started from January-March 2019.

A validated English questionnaire was used to collect data after getting the permission of Dr. Hind Almodaimegh, the main author of the previous research conducted at Riyadh, Saudi Arabia ${ }^{4}$. This questionnaire was modified in accordance with our research objectives and was sent to all health profession students who were studying in Jeddah city. We modified their questionnaire to ensure that it covered the objectives of the study. The questionnaire consisted of 20 closed MCQ items categorized under four sections: the first section was about the demographic data of the participants (age, gender, academic year, college name and specialty). The second section focused on the past medical history of the participants. The third section was about the causes and patterns of using propranolol. We asked about the causes of using propranolol (anxiety, exam stress, fear, tremors, blood pressure or other causes). Also, a propranolol usage pattern was identified. The fourth 
section was about the students' behavior and attitude about propranolol self-use (the recommendation of propranolol for other colleagues, medication side effects and complications).

The questionnaire was subjected to the process of face validation through five experts in Pharmacology and Medical Education specialties. Also, a pilot process of randomly selecting 20 students to whom the questionnaire was administered was conducted in Ibn Sina National College to ensure clarity of the questions. Then each item of the questionnaire was checked for vagueness and individuality in responses. This revealed that there was clarity and no confusion in the questions.

\subsection{Statistical Analysis}

Once the completed questionnaires were returned, they were entered into an Excel Spreadsheet. Data analysis was performed using the Statistical Package for the Social Sciences (SPSS version 25). The following methods were used, according to the type of data: Descriptive analysis by reporting the frequencies and percentages.

\subsection{Ethical Considerations}

Ethical clearance for the study was obtained from the ISNC Research and Ethics Committee (REF No: H-08-13022019). During the online survey, the participants were all informed about the purpose of the study and their right to refuse participation. Ethical conduct was maintained during data collection and throughout the research process. Participation in the study was voluntary and the confidentiality of the participants was maintained as the questionnaire was provided anonymously.

\section{Results}

The demographic data revealed that 271 (63\%) students who participated in the study $(n=430)$ were males, while the remaining 159 (37\%) students were females. $95.6 \%$ of the students were in the age group (20-30) years. The study population distribution according to their specialty was: Medicine students 203 (47\%), Pharm D students 116 (27\%) and Dentistry students $111(26 \%)$.

Table 1 reveals that the number of students who had a past medical history was $44(10 \%)$; about $22(50 \%)$ of them were having a migraine, and 15 (34\%) were having hypertension.

Figure 1 shows the prevalence of Propranolol usage among the studied population. Most of the students had not used propranolol $258(60 \%)$, whereas $172(40 \%)$ had used it for many reasons.

Figure 2 reveals that the most stressful educational situation was before poster or oral presentations $(73 ; 42 \%)$, then before practical/OSCE/OSPE exams $(45 ; 26 \%)$, then during final

Table 1. Presence of Past Medical History and distribution of certain diseases among study population $(n=430)$

\begin{tabular}{|l|c|r|r|}
\hline Variable & Category & \multicolumn{1}{l|}{ N } & \multicolumn{1}{l|}{$\%$} \\
\hline Health problem & Yes & 44 & 10.30 \\
& No & 386 & 89.70 \\
\hline Disease & Hypertension & 15 & 34.00 \\
& Migraine & 22 & 50.00 \\
& Angina & 3 & 07.00 \\
& Glaucoma & 4 & 09.00 \\
\hline
\end{tabular}

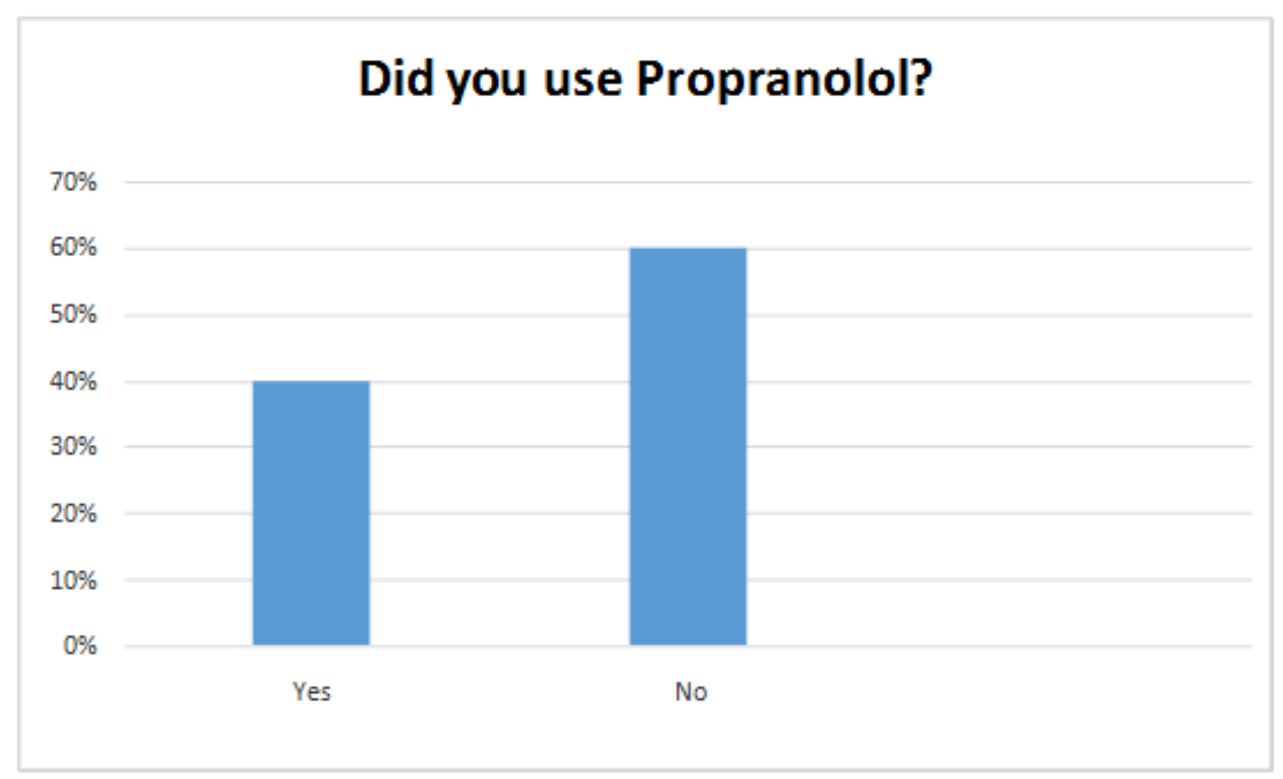

Figure 1. Prevalence of propranolol usage among the studied population $(n=430)$. 


\section{Educational Stress Situation}

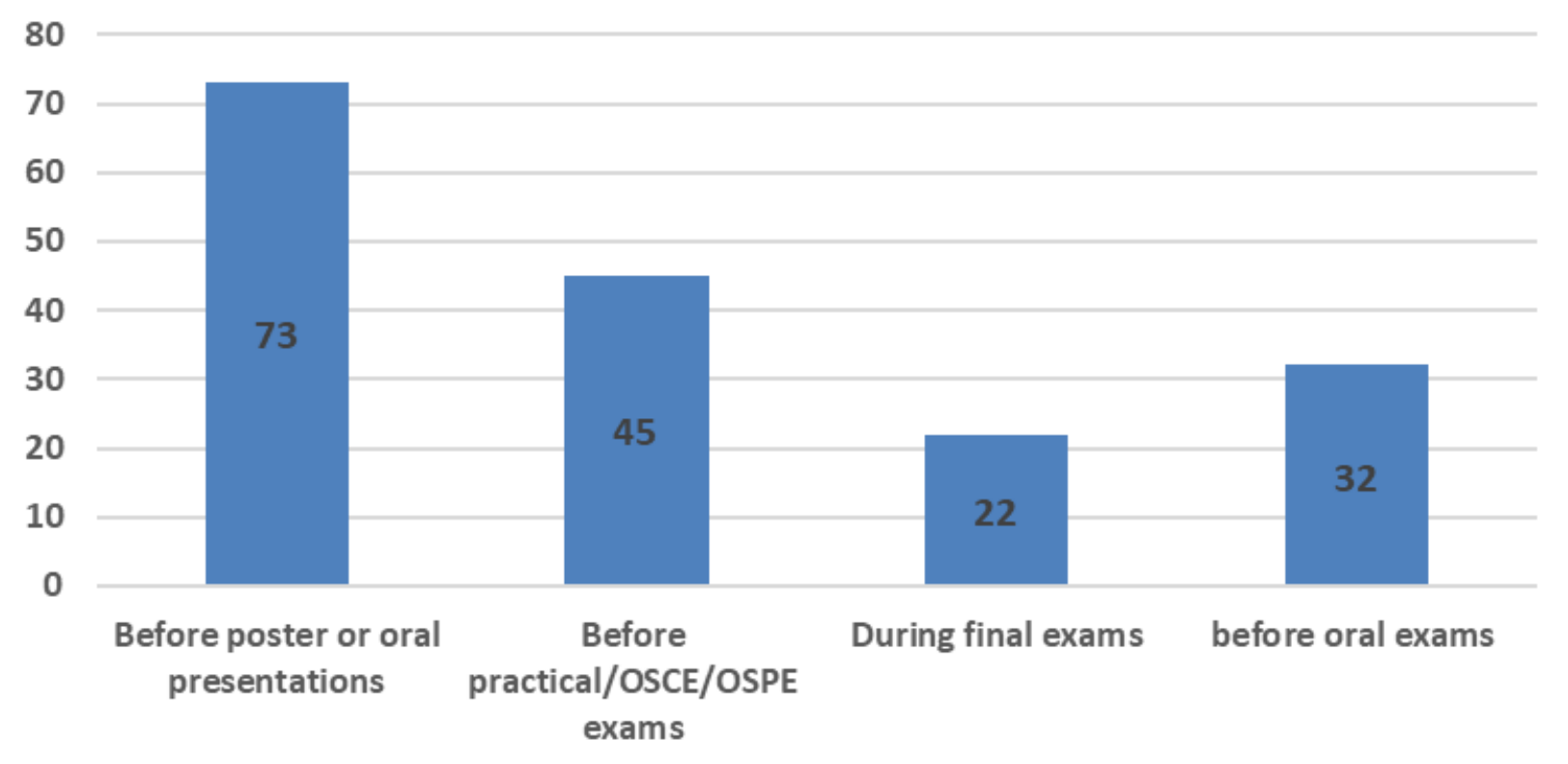

Figure 2. Prevalence of educational stress situations that stimulate students to use propranolol $(\mathrm{n}=172)$.

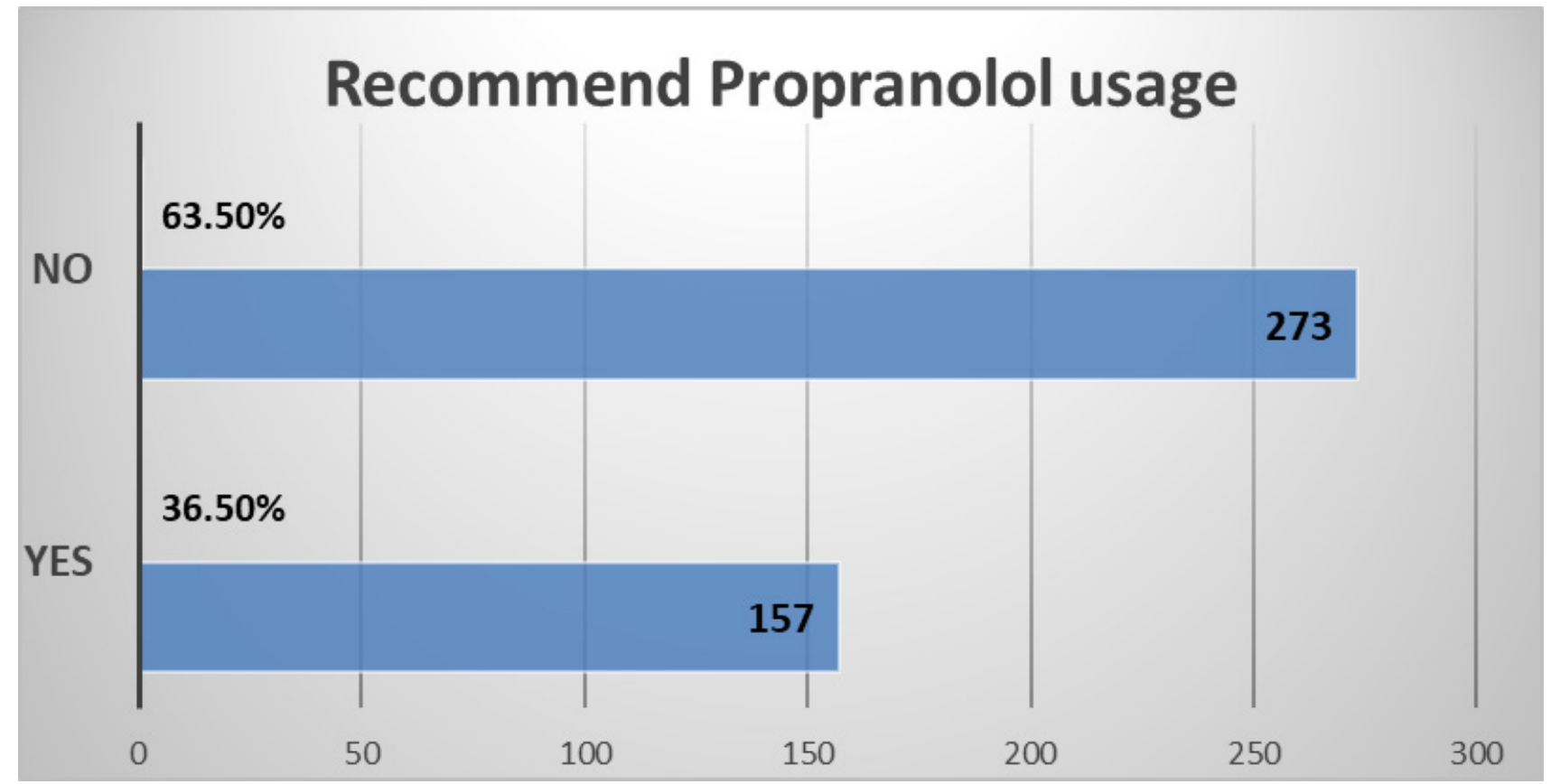

Figure 3. The recommendation percentage of propranolol usage among the study population $(n=430)$.

exams $(22 ; 13 \%)$ and the least stressful situation was before oral exams $(32 ; 19 \%)$.

Table 2 reveals many important results regarding the history and pattern of using propranolol for dealing with any educational stress and without any indication of a medical condition. There are 172 students (40\%) had used propranolol. $98(57 \%)$ of the students used propranolol prescribed by themselves, 44 (26\%) had the drug prescribed by their colleagues and 30 (17\%) of the study population used it according to their physician's prescription. 120 out of 172 students $(70 \%)$ reported that the most important cause of using propranolol during study time was stress and anxiety, then 33 students (19\%) reported that because of fear. Most of the students 78 (46\%) used a dose $<20 \mathrm{mg}, 56(32 \%)$ used a 
Table 2. History and patterns of using B-Blockers (Propranolol) $(\mathrm{n}=172)$

\begin{tabular}{|c|c|c|c|}
\hline Variable & Category & $\mathrm{N}$ & $\%$ \\
\hline \multirow[t]{3}{*}{ Who prescribed it? } & By yourself & 98 & 57.00 \\
\hline & By your physician & 30 & 17.00 \\
\hline & By your colleague & 44 & 26.00 \\
\hline \multirow[t]{4}{*}{ Reasons for its use } & Stress and anxiety & 120 & 70.00 \\
\hline & Fear & 33 & 19.00 \\
\hline & Blood pressure & 8 & 05.00 \\
\hline & Tremors & 11 & 06.00 \\
\hline \multirow[t]{5}{*}{ Dose } & $<20 \mathrm{mg}$ & 78 & 46.00 \\
\hline & $20 \mathrm{mg}$ & 56 & 32.00 \\
\hline & $40 \mathrm{mg}$ & 21 & 12.00 \\
\hline & $80 \mathrm{mg}$ & 1 & 00.50 \\
\hline & $\begin{array}{l}\text { Dose dependent } \\
\text { on activity }\end{array}$ & 16 & 09.50 \\
\hline \multirow{2}{*}{$\begin{array}{l}\text { Have you increased } \\
\text { the dose at any } \\
\text { time? }\end{array}$} & Yes & 29 & 17.00 \\
\hline & No & 143 & 83.00 \\
\hline \multirow{2}{*}{$\begin{array}{l}\text { Effective for } \\
\text { reducing stress }\end{array}$} & Yes & 148 & 86.00 \\
\hline & No & 24 & 14.00 \\
\hline \multirow[t]{2}{*}{ Side effects } & Yes & 54 & 31.00 \\
\hline & No & 118 & 69.00 \\
\hline \multirow[t]{5}{*}{ Side effects like } & Hypotension & 18 & 33.00 \\
\hline & $\begin{array}{l}\text { Shortness of } \\
\text { breath }\end{array}$ & 13 & 24.00 \\
\hline & $\begin{array}{l}\text { Erectile } \\
\text { dysfunction }\end{array}$ & 3 & 06.00 \\
\hline & Dry mouth & 13 & 24.00 \\
\hline & Others & 7 & 13.00 \\
\hline
\end{tabular}

dose of $20 \mathrm{mg}$ and 143 (83\%) didn't increase the propranolol dose. Most of the health profession students 148 (86\%) agreed that propranolol is effective in reducing the educational stress and 118 (69\%) agreed that it had no side effects on their health. Among those students who reported propranolol side effects, 18 students (33\%) agreed that the most common side effects are hypotension, then shortness of breath 13 (24\%) and dry mouth 13 (24\%).

Figure 3 shows that the majority of health profession students 273 (63.50\%) didn't agree to recommend propranolol usage for their colleagues.
Figure 4 shows that the most important reasons they did not recommend propranolol for their colleagues were the propranolol side effects, as expressed by 255 (59\%) of them, then because its use is illegal without any medical prescription, as in the case of 100 students (23\%).

\section{Discussion}

This study demonstrated the prevalence of the self-use of propranolol among health profession students who study in Jeddah city, Saudi Arabia. According to our information, this is the first known research work conducted about the prevalence, pattern and attitude of health profession students towards the use of propranolol to relieve their educational stress and anxiety during study time.

The study results revealed that $40 \%$ (172) of the study population were using propranolol and 89\% (153) of them were in the age group 20-30 years. This is in comparison with another study done in Saudi Arabia, which measured the prevalence of self-prescribing propranolol among medical and dental students at Riyadh city, with their results revealing that $30 \%$ (100 out of 334) of dental and medical students used propranolol (Inderal) during their college years ${ }^{4}$.

Whereas medical students were more likely to be propranolol users than dental students (97\%). According to that research work ${ }^{4}$ our results revealed that all propranolol users in our study were from the medicine specialty (100\%). Notably, the clinical year students were more prone to using the drug than basic year students.

Our study results revealed that the most causative stimulants to use propranolol among the medical students were for reducing the educational stress and anxiety (70\%), and they reported that they more frequently used before oral/ poster presentation (42\%) and entering the practical exams (OSCE/OSPE) (26\%) and oral exam (19\%), in comparison to the theoretical written exam (P-value $<0.01)$. This is in consonance with the results of different studies conducted about educational stress prevalence, among medical students especially. In a study conducted about the psychological distress and lifestyle of Malay medical students, the results revealed that about a third $(34.9 \%)$ of medical students were facing stress during the time of study, with $(6.8 \%)$ of them experiencing severe to extremely severe stress during study time $^{12}$. This rate of stress was lower compared to another study, which reported that (47.9\%) of medical students at Antalya, Turkey suffered from stress during college years ${ }^{13}$. On the other hand, the levels of stress were higher than a study in Thailand which found about $(61.4 \%)$ of medical students had some degree of stress whereas (2.4\%) of them reported a high level of stress during the oral exam performance ${ }^{14}$. One study reported that the higher anxiety and stress level associated with the 


\section{Reasons that they didn't recommend}

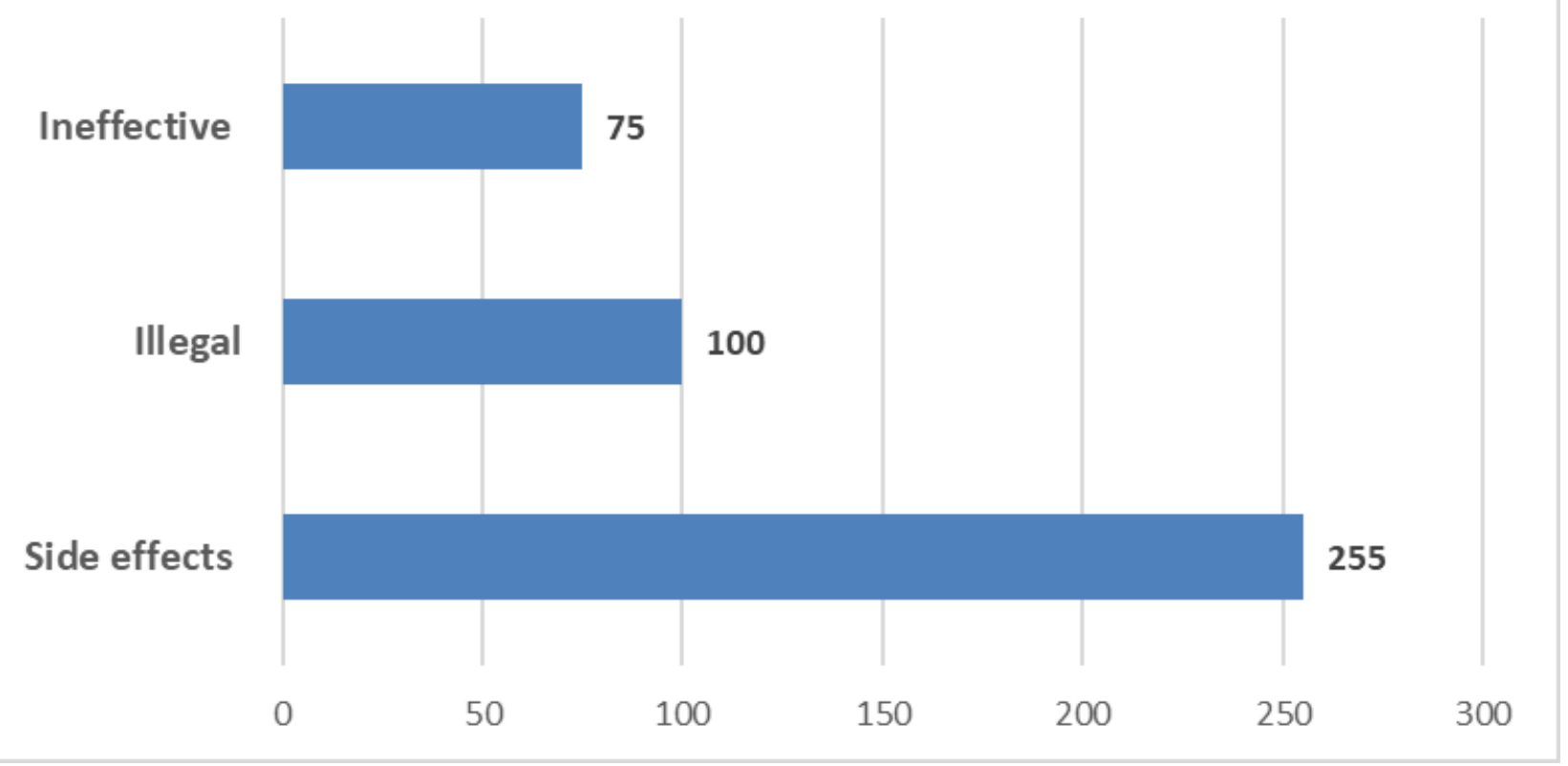

Figure 4. The reasons for not recommend Propranolol usage among the study population $(\mathrm{n}=430)$.

OSCE exam contributes to fewer efficacies and decreases the confidence level of the students taking this OSCE examination compared to those appearing in traditional examinations like Multiple-Choice Questions ${ }^{15}$.

As regards propranolol use, predictors have revealed that more males were using propranolol (78\%) among medical and dental students at Riyadh research (4), and this is concurrent with our results, as most users of propranolol were male medical students $(84 \%)$, in contrast, to another study conducted about drug abuse among university students of Rafsanjan, Iran; that research work reported that female students had higher rates of propanol use compared to the male students ${ }^{10}$. Female students in preclinical years have a greater ability to manage stress than male students, according to a Malay medical school study ${ }^{12}$.

Also, a recent study conducted about substance use for cognitive enhancement by university students in the Netherlands revealed that most university students use one or the other drug substance without any medical indication or prescription with the intention of cognitive enhancement. In this study, prescription drugs, illicit drugs, and lifestyle drugs were found to have been used respectively by (1.7\%), (1.3\%) and $(45.6 \%)$ of the sample. The authors also found evidence of poly-drug use concerning cognitive enhancement. There is an evident relationship between stress and the use of lifestyle drugs for cognitive enhancement ${ }^{9}$.

Our study revealed that (57\%) of the students were on propranolol use prescribed by themselves without any medical indication or physician prescription. The prevalence of using propranolol was (40\%) among all health profession students in Jeddah city. It has been reported in different studies that non-medical prescription of propranolol is common among medical students. Although the prevalence of propranolol misuse differs in different studies, they have reported the prevalence of use of beta-blockers in Riyadh city at $(30 \%)^{4}$ Iran $(4.7 \%)^{10}$, Switzerland $(1.2 \%)^{11}$ and the Netherlands $(61.1 \%)^{9}$.

About 78 students (46\%) reported that they use less than $20 \mathrm{mg}$ of propranolol and they agreed that this low dose is very effective in reducing their education related stress, so that they did not need to increase the dose (83\%). Although 54 out of $172(31 \%)$ of the propranolol users were completely aware of the drug side effects, only (36.5\%) of them would recommend this drug for their medical colleagues even in this low dose before any stress-related educational situations like OSCE/ OSPE, clinical exam and oral/poster presentation.

The study was conducted among health profession students who were aware of the hazards of B-blockers' self-use and they showed increased misuse of propranolol, especially among Medical students than Dental and Pharm D students in Jeddah city. This needs massive reorientation and change in their attitude to avoid the misuse and overuse of this drug without any medical indication or health condition. This orientation program should target all higher education institutions in Saudi Arabia and other parts of the world. 


\section{Conclusion}

Stress can affect students' academic achievement and wellbeing, and excessive stress can seriously and negatively impact a student's health and educational performance. An optimal level of stress could enhance deep learning and good achievement, whereas excessive amounts of stress could affect the students' academic achievement and may lead to serious mental and physical health problems. Medical students always seek solutions to overcome these stressful educational situations they face during their study, through the self-use of B blockers (propranolol) due to its efficacy in relieving such stress. This study concludes that there is a slightly high rate of propranolol misuse among health profession students in Jeddah city. All users are aware of the risks and potential side effects of propranolol; however, the stress-relieving effects and feeling of propranolol have increased its use by health profession students before practical, clinical, oral and presentations exams.

We suggest the organization of educational campaigns by Pharm D students inside the ISNC campus and other health professional institutions in Jeddah city about the hazards and risks of misuse of B-Blockers (propranolol) without the presence of any medical indication. Also, we recommend the implementation of awareness and support programs to help all higher education students cope with the different types of educational stress they face during the study period, by using non-harmful and nonpharmacological rather than harmful drugs.

\section{Limitations of the Study}

Some limitations should be acknowledged that if overcome could lead to better findings: first, the small sample size hindered generalizability of the results. So, repetition of similar research work on national and international levels is needed.

\section{Acknowledgments}

The authors would like to thank Dr. Hind Almodaimegh, Assistant Dean, College of Pharmacy, King Saud Bin AbdulAziz University for Health Sciences, Riyadh, Saudi Arabia for her support from the start of the research work. Also, the research team would like to extend their sincere appreciation to the Deanship of Ibn Sina National College, Jeddah, Saudi Arabia.

\section{Financial resource}

The research team declares no presence of any financial support or funding agents' relationships that may pose any conflict of interest in the future.

\section{Conflict of Interest}

The authors have no conflict of interest, and the work was not supported or funded by any organization.

\section{References}

1. Kakunje A. Stress among health care professionals - The need for resiliency. Online J. Health Allied Scs. 2011; 10 (1): 1.

2. Pereira MA, Barbosa MA. Teaching strategies for coping with stress the perceptions of medical students. BMC Med. Educ. Journal. 2013; 13: 50. https://doi.org/10.1186/1472-6920-13-50. PMid: 23565944, PMCid: PMC3627623.

3. Mark AM. Modeling Doctor of Pharmacy Students'stress, satisfaction, and professional attitudes survey. American J. of Pharma Educ. 2016; 80(5). Article S2.

4. Al-Mohrej OA, et al. Prevalence of self-prescribing propranolol among medical and dental students in Riyadh, Saudi Arabia: A cross-sectional study. Health Prof. Educ. J. 2016. https://doi. org/10.1016/j.hpe.2016.10.001.

5. Black JW, Stephenson JS. Pharmacology of a new adrenergic beta-receptor-blocking compound (Nethalide). Lancet. 1962; 280(7251): 311-314. https://doi.org/10.1016/S0140-6736(62) 90103-4.

6. Johansen JP, Cain CK, Ostroff LE, LeDoux JE. Molecular mechanisms of fear learning and memory. Cell Journal. 2011; 147: 509-524. https://doi.org/10.1016/j.cell.2011.10.009. PMid: 22036561, PMCid: PMC3215943.

7. Asheesh Kumar, Ajit Joshi, Starling SK. $\beta$-Blockers: A systematic review. J. Chem. Pharm. Res. 2011; 3(1): 32-47.

8. Alexander JK, Hillier A, Smith RM, Tivarus ME, Beversdorf DQ. The beta-adrenergic module at ion of cognitive flexibility during stress. J. Cogn. Neuro Sci. 2007; 19(3): 468-478.https://doi. org/10.1162/jocn.2007.19.3.468. PMid: 17335395.

9. Schelle KJ, Olthof BMJ, Reintjes W, Bundt C, Gusman-Vermeer J, van MilACCM. A survey of substance uses for cognitive enhancement by university students in the Netherlands. Front Syst. Neurosci.2015;9: 1-11.https://doi.org/10.3389/fnsys.2015.00010. PMid: 25741248, PMCid: PMC4330699.

10. Rezahosseini O, Roohbakhsh A, Tavakolian V, Assar S. Drug abuse among university students of Rafsanjan, Iran. Iran J. Psych. Behav. Sci. 2014; 8(2): 81-85.

11. Maier LJ, Liechti ME, Herzig F, Schaub MP. To dope or not to dope: Neuro enhancement with prescription drugs and drugs of abuse among Swiss university students. PLOS One. 2013; 8(11): e77967. http://dx.doi.org/10.1371/journal.pone.0077967. PMid: 24236008, PMCid: PMC3827185.

12. Salmi Razali, et al. Psychological distress and lifestyle of Malay Medical Students. Med. Educ. J. Spring. 2016; 15(2).

13. Aktekin M, Karaman T, Senol YY, Erdem S, Erengin H, Akaydin M. Anxiety, depression and stressful life events among medical students: A prospective study in Antalya, Turkey. Med. Edu. J. 2001; 35(1): 12-7. https://doi.org/10.1046/j.13652923.2001.00726.x. 
14. Saipanish, R. Stress among medical students in a Thai Medical School. Med. Teach. J. 2003; 25(5): 502-506. https://doi.org/10.10 80/0142159031000136716. PMid: 14522672.
15. Mavis B. Self-efficacy and OSCE performance among secondyear medical students. Adv. Health Sci. Educ. Theory Pract. 2001; 6(2): 93-102. https://doi.org/10.1023/A:1011404132508. PMid: 11435761 . 